\title{
Política externa e diplomacia brasileira no século XXI: \\ 37 questões em pauta - Entrevista com o Embaixador Paulo Roberto \\ de Almeida
}

Foreign policy and Brazilian diplomacy in the 21st century:

Interview with Ambassador Paulo Roberto de Almeida

Entrevistador: Gunter $\mathrm{Axt}^{1}$

Submetido em 19 e aprovado em 29 de abril de 2020.

Resumo: A entrevista é com Paulo Roberto de Almeida, Doutor em Ciências Sociais (Université Libre de Bruxelles, 1984), diplomata de carreira do Brasil desde 1977. Serviu em diversos postos no exterior e exerceu funções na Secretaria de Estado, geralmente nas áreas de comércio, integração, finanças e investimentos. Foi professor de Sociologia Política no Instituto Rio Branco e na Universidade de Brasília (1986-87) e, desde 2004, é professor de Economia Política no Programa de Pós-Graduação (Mestrado e Doutorado) em Direito do Centro Universitário de Brasília (Uniceub). É editor adjunto da Revista Brasileira de Política Internacional. A entrevista, realizada em abril de 2020, por Gunter Axt, discute aspectos da política externa e da diplomacia do Brasil no século XXI, sendo as relações bilaterais com o Canadá contempladas na análise.

Palavras-chave: Paulo Roberto de Almeida. Itamaraty. Brasil. Canadá. Relações exteriores.

\begin{abstract}
The interview is with Paulo Roberto de Almeida, $\mathrm{PhD}$ in Social Sciences (Université Libre de Bruxelles, 1984), a career diplomat in Brazil since 1977. He has served in several posts abroad and served in the Secretary of State, generally in the areas of trade, integration, finance and investment. He was a professor of Political Sociology at the Rio Branco Institute and at the University of Brasília (1986-87) and, since 2004, he has been a professor of Political Economy in the Postgraduate Program (Master and Doctorate) in Law at the University Center of Brasília (Uniceub). He is associate editor of the Brazilian Journal of International Politics. The interview, conducted in April 2020, by Gunter Axt, discusses aspects of Brazilian foreign policy and diplomacy in the 21st century, with attention to the bilateral relations with Canada.
\end{abstract}

Keywords: Paulo Roberto de Almeida. Itamaraty. Brazil. Canada. Foreign relations. 
Paulo Roberto de Almeida é Doutor em Ciências Sociais (Université Libre de Bruxelles, 1984), Mestre em Planejamento Econômico (Universidade de Antuérpia, 1977), Licenciado em Ciências Sociais pela Université Libre de Bruxelles, 1975). É diplomata de carreira, por concurso direto, desde 1977. Serviu em diversos postos no exterior e exerceu funções na Secretaria de Estado, geralmente nas áreas de comércio, integração, finanças e investimentos. Foi professor de Sociologia Política no Instituto Rio Branco e na Universidade de Brasília (1986-87) e, desde 2004, é professor de Economia Política no Programa de Pós-Graduação (Mestrado e Doutorado) em Direito do Centro Universitário de Brasília (Uniceub). É editor adjunto da Revista Brasileira de Política Internacional, colabora com várias iniciativas no campo das Humanidades e Ciências Sociais, e participa de comitês editoriais de diversas publicações acadêmicas. De agosto de 2016 a março de 2019 foi Diretor do Instituto Brasileiro de Relações Internacionais (IPRI), afiliado à Fundação Alexandre de Gusmão (Funag), do Ministério das Relações Exteriores. Tem diversos livros publicados, sendo os mais recentes Marxismo e socialismo: trajetória de duas parábolas da era contemporânea (Brasília: Edição de Autor, 2019) e Miséria da diplomacia: a destruição da inteligência no Itamaraty (Boa Vista: Editora da UFRR, 2019). Mantém o blog Diplomatizzando. A entrevista, concluída em 5 em abril de 2020, discute aspectos da política externa e da diplomacia do Brasil no século XXI, sendo as relações bilaterais com o Canadá contempladas na análise. 


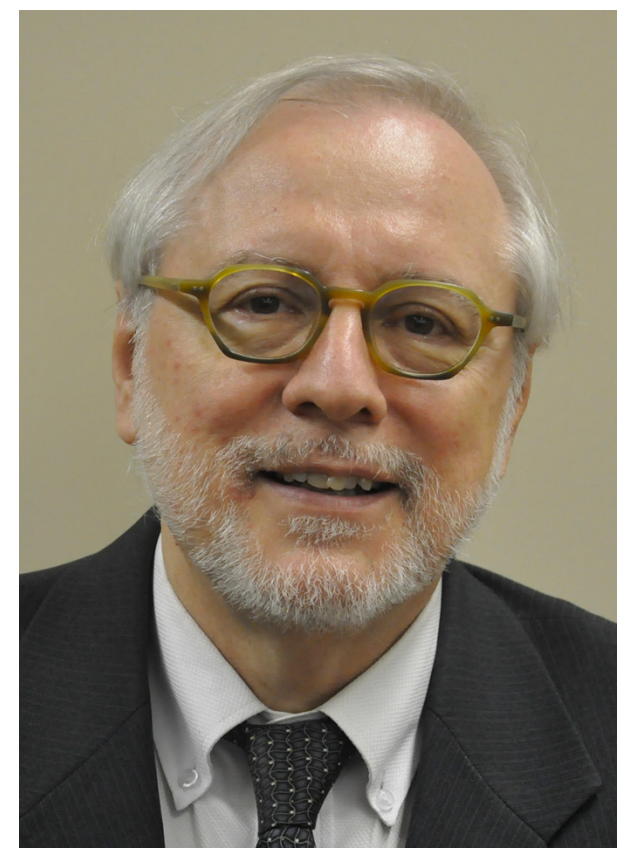

Em sua opinião, quais foram os principais problemas das gestões Lula e Dilma? Nas redes sociais, fala-se muito nos empréstimos do BNDES a projetos executados em países como Cuba, Venezuela, Moçambique... Qual a responsabilidade da política exterior sobre esses casos? Como você viu a proximidade de Lula com ditadores como Maduro, Kadafi, Robert Mugabe, Denis Nguesso e Teodoro Obiang?

PRA: Um (existem vários outros) dos principais problemas da política externa e da diplomacia brasileira sob o lulopetismo foi a preservação de uma visão do mundo tipicamente Norte-Sul, ou seja, uma divisão das relações internacionais entre países ditos hegemônicos, de um lado - antigos impérios coloniais, e novas potências imperialistas - e países dependentes, ou periféricos, de outro, e uma atuação diplomática no sentido de fazer do Brasil, ainda e sempre, um líder dos países do Sul, adotando divisões anacrônicas que poderiam ter algum sentido na criação da $\mathrm{ONU}$, em 1945, mas sem muita sustentação prática mais de 70 anos depois. Daí decorreu uma ofensiva em direção aos "não-hegemônicos", como se estes, apenas pela "virtude" de 
não terem sido grandes potências teriam necessariamente uma identidade comum e interesses convergentes. A tentativa de liderar um bloco sul-americano foi pronta e devidamente sabotada pelos vizinhos, embora o Brasil, como grande economia, tenha tido grande sucesso na África, inclusive porque a aproximação vinha com promessas de ajuda, ou oferecimento de benesses desse tipo. O presidente Lula cancelou a dívida bilateral do Gabão, à época dirigido há quase meio século pelo mesmo ditador, de um país exportador de petróleo e, portanto, provido de recursos em divisas. Outros países também foram contemplados com o mesmo benefício que, cabe registrar, se fez em detrimento do Tesouro e, portanto, das contas públicas nacionais. Tratou-se de um típico caso de imposição autoritária por um presidente, sem consulta aos técnicos do Tesouro ou aos diplomatas do setor. Típica medida de populismo demagógico.

Dilma consumiu oito ou nove meses para receber credenciais de diplomatas (levou tempo semelhante para escolher ministros do STF e do STM) e desfeiteou no último minuto o Embaixador da Indonésia. O que isso significa e termos diplomáticos, no curto e no longo prazo? É questão plenamente superada?

PRA: A presidente Dilma tinha especial prazer em desconsiderar as normas e costumes diplomáticos, assim como ela tinha desprezo pelos diplomatas e pelo Serviço Exterior. Esse atraso no recebimento de credenciais representa uma descortesia monumental no plano das relações bilaterais, assim como em conexão com normas usualmente seguidas nas relações internacionais, reguladas, nesse plano, pela Convenção de Viena sobre Relações Diplomáticas (1961). São atitudes arrogantes e sem qualquer sustentação no quadro da simples civilidade.

Um dos temas mais controversos do período foi a venda da refinaria da Petrobras na Bolívia por USD 112 milhões, valor que muitos consideraram abaixo do mercado e aquém dos investimentos lá realizados pela petroleira. Depois da ocupação militar das refinarias por Evo Morales, Lula chegou a dizer que o Acre fora trocado por um cavalo, o que parece injusto com Plácido de Castro, Joaquim Francisco de Assis Brasil e Rio Branco. O Embaixador Rubens Barbosa chegou na época a falar (em tom crítico) em uma "diplomacia da generosidade". Por outro 
lado, uma crise diplomática com um vizinho com baixa autoestima foi contornada. O que ficou desse episódio? Houve prejuízo, foi menos significativo que os ganhos? Há casos onde nossos prejuízos foram maiores?

PRA: O caso ainda está relativamente obscuro, pois pode ter sido precedido de entendimentos prévios, diretos, entre Lula e Morales, este instruído e animado por Chávez (e sustentado por Nestor Kirchner, que tinha raiva de Lula), aquele achando que estava construindo a sua liderança na região. O fato é que a Bolívia rasgou um tratado bilateral, sem atentar para os dispositivos de denúncia, e também um acordo entre o governo boliviano e a Petrobras. Um dia depois, não o Itamaraty, mas o governo brasileiro emitiu uma nota vergonhosa aprovando a atitude unilateral da Bolívia. Um mês depois, uma reunião bilateral para tratar da questão da indenização teve como presidente da delegação brasileira o assessor presidencial Marco Aurélio Garcia, que assumiu inteiramente a posição boliviana, para choque e estupor dos demais membros da delegação e sobretudo da Petrobras. Esta foi impedida de recorrer ao acordo de proteção de investimentos entre a Holanda e a Bolívia - pois que os investimentos da Petrobras tinham sido feitos por uma holding da empresa na Holanda, justamente por haver um acordo desse tipo, quando o PT opôs-se resolutamente a qualquer acordo desse tipo - e teve de aceitar um enorme prejuízo, uma vez que mesmo tendo feito investimentos adicionais, após a aquisição de patrimônio do governo boliviano, ela não recebeu nenhum pagamento, apenas entregas de gás, e num preço reajustado para cima, por concessão unilateral do governo Lula. Ou seja, o Lula atuou como um traidor da nação, como um violador da legislação brasileira, assim como Morales o foi do Direito Internacional. Os prejuízos materiais foram grandes para a Bolívia, mas aqueles que incidiram sobre a nossa diplomacia foram ainda maiores. Poucos dias depois da nacionalização, Lula compareceu a um vergonhoso encontro em Puerto Iguazu, na Argentina, onde foi humilhado por Chávez e Kirchner, ao ter de aceitar todas as condições impostas por Morales e sustentadas pelos dois outros, que não tinham nada a ver com a questão bilateral. Esse foi um momento vergonhoso para a nossa diplomacia. 
Por outro lado, no período Lula-Dilma o Brasil investiu como nunca no multilateralismo, gozou de prestígio internacional e seu soft Power nunca esteve tão vitaminado. Qual o legado positivo dessa época?

PRA: De fato, o Brasil teve uma grande projeção internacional, dada a diplomacia extremamente ativa de Lula e Celso Amorim; Dilma representou um ponto baixo nessa trajetória. Foi positiva para a imagem internacional do Brasil, mas muitas iniciativas foram puramente retóricas e de propaganda, com poucos efeitos práticos, como o IBAS (Fórum de Diálogo Índia, Brasil e África do Sul ), por exemplo. Mesmo o BRICS trouxe efeitos de imagem, mas escassos resultados positivos, inclusive considerando o Banco: não é dinheiro que falta para impulsionar o desenvolvimento, e sim projetos solidamente construídos. Foram gastos milhões de dólares com passagens e diárias de burocratas e outros enviados (acadêmicos inclusive) sem qualquer benefício para o povo brasileiro, apenas efeito propaganda do presidente.

Nossa história registra diplomatas que divergiram de governos. Normalmente, contudo, espera-se de diplomatas (assim como de militares e juízes) que evitem emitir opiniões a respeito dos governos aos quais devem obediência. Você não é exatamente adepto dessa orientação, mantendo um blog, de resto, inclusive, como fazia o atual chanceler, Ernesto Araújo, antes de empossado no cargo. Em março de 2019 você foi desligado sem explicações do Instituto de Pesquisas e Relações Internacionais - IPRI. Foi uma retaliação aos seus comentários e críticas? Por sua vez, não conheço avaliações críticas de Audo Araújo Faleiro, desligado quatro dias depois de ser nomeado para a chefia da Divisão de Europa do Itamaraty, por pressão das redes sociais, apenas porque teria, ao que se divulgou, trabalhado com Marco Aurélio Garcia, no exercício de função de estado. Qual o limite para a divergência de um diplomata? Está havendo no Itamaraty perseguição ideológica?

PRA: Como costumo dizer, o Itamaraty não é de esquerda, nem de direita, ele é feudal, no sentido de preservar a hierarquia com a dominação dos "barões da Casa" e o temor reverencial por parte dos "servos de gleba", que dependem daqueles para sua ascensão funcional, para boas remoções e postos de chefia. Normalmente, diplomatas 
não são esquerdistas, nem direitistas, eles são carreiristas, alguns até oportunistas, em todos os sentidos da palavra. Na época lulopetista, ocorreu uma moderada seleção de assessores por simpatias pessoais ou afinidades ideológicas, ainda que alguns, como sempre, tenham construído essa identidade para objetivos momentâneos. Poucos foram hostilizados, mas muitos foram afastados ou desviados de postos importantes, em favor daqueles mais alinhados, pessoal ou politicamente, aos donos do poder naquele momento. O caso de Audo é típico da era lulopetistas, pois foi beneficiado pelo regime, enquanto este tinha proeminência; agora foi vergonhosamente discriminado pelos novos cruzados da direita. Meu caso é diferente, pois sempre pensei com minha própria cabeça e nunca me submeti ao ritual tradicional de submissão aos chefes da Casa, expressando minha própria opinião sobre todos os assuntos. Fui "censurado" na ditadura - tendo de escrever sob outros nomes - e na redemocratização - cortes de parágrafos em livros e artigos meus -, depois punido em pleno regime democrático de FHC, por ter publicado sem atentar para a famosa "Lei da Mordaça" - circular que impunha controle prévio de qualquer manifestação pública -, mas que simplesmente consistiu em telegramas de advertência, que vão para o maço pessoal. No regime lulopetista recebi a pior das punições, nada formalizada, simplesmente a não atribuição de cargos na Secretaria de Estado das Relações Exteriores (SERE), durante todo o regime, tendo permanecido anos e anos na Biblioteca. Finalmente, o quadro se repete da pior maneira no novo regime bolsonarista, quando também fui afastado de qualquer cargo e formalmente lotado na Divisão do Arquivo, o que foi feito para me humilhar obviamente. Voltei a trabalhar na biblioteca, mas tive a surpresa de enfrentar descontos financeiros, por supostas faltas e atrasos em um trabalho que simplesmente não existe, o que me obrigou a introduzir uma medida judicial contra a União, no caso representada pelo Ministério das Relações Exteriores. Todas essas etapas e episódios estão amplamente documentados em minhas páginas de comunicação social.

Uma diretriz importante estabelecida por Rio Branco foi a abstenção nos assuntos internos das nações vizinhas, de modo a favorecer a estabilidade regional, prestigiando os governos constitucionais, quaisquer que fossem eles. Quando o Presidente se imiscui na campanha eleitoral argentina, precipita-se no reconhecimento 
de um autoproclamado presidente na Venezuela (emitindo, inclusive, por meio de seu chanceler, sinais de que poderia estar disposto a participar de uma intervenção armada nesse país), e o filho ex-futuro-embaixador em Washington insinua apoio à invasão da embaixada da Venezuela em Brasília, a diretriz de Rio Branco está sendo abandonada?

PRA: A diplomacia profissional brasileira, ao longo do século $\mathrm{XX}$, construiu uma política de não intervenção nos assuntos internos de outros países - uma postura até constitucionalizada formalmente no Art. 4 da CF-1988 - que se tornou praticamente o padrão básico de nosso comportamento bilateral, regional e multilateral. Esse princípio foi amplamente violado na era Lula, pois ele sistematicamente imiscuiu-se na política interna dos vizinhos, apoiando candidatos de suas simpatias políticas, o que pode ser configurado como uma postura contrária às normas diplomáticas e anticonstitucional. Ao que parece, o governo Bolsonaro segue o mesmo padrão ilegal e ilegítimo, também por razões claramente ideológicas, que no caso são absolutamente estúpidas no plano das relações diplomáticas bilaterais.

O atual chanceler tem sido apontado por analistas como personagem despreparado para o cargo e até lunático, não apenas no Brasil, mas no exterior, como escancarou recente matéria no The Guardian. Você concordaria com essa avaliação? Acredita que a contenção que militares se propuseram a fazer sobre ele no início do governo, contornando possíveis crises severas e desnecessárias, como com a Venezuela ou com os países árabes, esteja funcionando?

PRA: O governo Bolsonaro escolheu como chanceler um diplomata sem experiência e sem equilíbrio emocional suficiente para exercer o cargo. Está claro que ele forjou uma identidade olavista, e se submeteu a uma extraordinária submissão aos membros da família presidencial, para ganhar o seu cargo, o que o torna totalmente ilegítimo do ponto de vista da expressão das posturas mais técnicas por parte do corpo de diplomatas profissionais. São evidentes os sinais de desequilíbrio pessoal e de dúvidas e hesitações - dado o conflito interno entre sua trajetória diplomática anterior e as orientações claramente desajustadas do grupo no poder - no tratamento de diversos 
assuntos inscritos na agenda internacional do Brasil. O choque foi especialmente forte logo ao início do governo, quando o chanceler tentou forçar uma adesão indesejada pelos militares à aventura eleitoreira de Trump na Venezuela, o que foi objeto de um "cordão sanitário" em torno do chanceler. As fricções continuam, sobretudo em decorrência das orientações claramente equivocadas do presidente e sua família, o que obriga setores mais racionais - militares, agronegócio, empresários em geral - a se esforçarem para conter as medidas mais inadequadas do ponto de vista dos negócios.

Como você interpreta o gesto do chanceler brasileiro que foi aos Estados Unidos discutir a minuta do discurso do Presidente Bolsonaro na ONU com Steve Bannon?

PRA: Gesto absolutamente inédito nos anais da diplomacia brasileira e totalmente desprezível do ponto de vista da autonomia nacional na determinação de suas principais diretrizes externas. É a subserviência em seu estado puro, algo vergonhoso para nossa diplomacia profissional.

O Pacto Amazônico funciona? Ao invés de investirmos em uma narrativa paranoica em relação à Amazônia, não poderíamos estar atraindo investimentos e fortalecendo nossa imagem internacional com a floresta em pé e com um diálogo com o planeta sobre a sustentabilidade da região?

PRA: Sim, existe um Tratado de Cooperação Amazônica (1978) e existe uma organização para implementar os dispositivos do tratado (OTCA, cuja sede está em Brasília), mas ambos foram ignorados, inclusive porque o governo é autista, totalmente introvertido, e despreza o direito internacional e o multilateralismo. O soberanismo patriótico é absolutamente ridículo nesse contexto.

Como você avalia o desempenho do Brasil na COP-25 (Conferência das Nações Unidas sobre Mudanças Climáticas)?

PRA: Desde o início do governo Bolsonaro, a postura ambientalista do Brasil é de um regressismo assustador, colocando o país na contramão das tendências mais aceitas no plano internacional. Essa postura deve acarretar prejuízos econômicos e comerciais. 
Nove estados da região amazônica celebraram um convênio com a França. Qual o sentido desse movimento?

PRA: Na verdade, o que prevalece é uma grande confusão e uma total falta de liderança e de coordenação por parte do governo federal. Esse é o resultado de um presidente inapto, inepto, incapaz de formular ou dirigir políticas públicas racionais.

Qual o impacto que o conjunto da política brasileira para o Meio Ambiente pode ter sobre a retomada do crescimento da nossa economia, muito especialmente sobre a atração de investimentos externos?

PRA: O governo atual parece desconhecer que o "politicamente correto", por mais exagerado e até inconveniente que possa parecer, tornou-se uma imposição crescente para atores públicos e privados, sobretudo e principalmente na área ambiental, o que significa que os contraventores, estados ou empresas, serão severamente punidos pela opinião pública, o que repercutirá nas relações comerciais e até de cooperação cultural, científica e política, de modo geral.

Como você percebe a agressividade do Presidente Bolsonaro a dirigentes estrangeiros, como no seu discurso na ONU, mas também nos episódios envolvendo a ex-presidente Bachelet e a primeira-dama da França, sem mencionar os ataques à Alemanha, Noruega e Dinamarca?

PRA: Discurso totalmente ridículo, feito por assessores incompetentes, e apenas visto por um chanceler sem qualquer poder, absolutamente voltado para o público interno e desconhecendo totalmente as normas básicas das relações internacionais. Basta comparar esse discurso com todos os precedentes em todos os anos de AGNU, para evidenciar como ele está totalmente fora do padrão. Além de inadequado, foi grosseiro, descortês, rude.

A prestigiosa revista alemã Der Spiegel mencionou que o Brasil estaria se tornando um pária global. Você entende que isso pode acontecer, ou já aconteceu?

PRA: O Brasil infelizmente sofre as consequências de um presidente que é, sim, um pária internacional, com poucas exceções, apenas aquelas de "amigos", ou aliados de extrema direita e claramente personalidades autoritárias como ele. Isso quer dizer, 
simplesmente, que ele não irá receber NENHUM convite para visita de Estado, ou mesmo de trabalho, dos mais importantes parceiros do Brasil - a não ser alguns, por interesse próprio -, e em consequência o Brasil e os brasileiros não mais poderão se beneficiar de eventuais acordos de cooperação.

Ataques a representações diplomáticas brasileiras são historicamente incomuns. Nas em 2019, tivemos ataques em Berlim, Wellington e Londres, além de manifestações em diversas cidades pelo mundo, em agosto. Como isso afeta a imagem do país?

PRA: Lamentável o espetáculo, de um lado e de outro. O presidente Bolsonaro, infelizmente, desperta total rejeição em amplos setores da opinião pública internacional e como tal projeta essa rejeição sobre nossas representações no exterior. Lamentável que os diplomatas tenham de assistir a um espetáculo de rejeição que simplesmente não existiria se o presidente fosse minimamente responsável.

\section{Qual sua opinião sobre o tratado com a União Europeia?}

PRA: Não é nem um acordo de livre comércio, e sim de liberalização parcial, administrada, de determinados fluxos de comércio, mais próximo do mercantilismo do que do verdadeiro livre comércio. Independentemente de cotas, exceções, delongas em setores específicos, o fato é que não se tem sequer certeza de que esse acordo poderá entrar em vigor, dado, por um lado, o protecionismo tradicional (dos dois lados), mas sobretudo em função da postura ambientalista do governo Bolsonaro, o que tem motivado alguns países, ou parlamentos, a rejeitar a sua aceitação (e todos os membros da EU precisam fazê-lo). Minha percepção de que enquanto Bolsonaro estiver no poder, esse acordo tem poucas chances de ser implementado. $\mathrm{O}$ acordo, aliás, só surgiu, finalmente, no contexto da chamada "guerra comercial" entre os EUA e a China, e se esse contexto for superado, pode ser que sua urgência se torne menor, do ponto de vista puramente político.

O Brasil ensaiou algumas vezes no passado alinhamentos automáticos com os Estados Unidos, como logo depois do golpe militar que instalou a República e durante parte do governo Dutra, quando uma das consequências foi a pulverização 
das reservas cambiais acumuladas durante a Segunda Guerra. A exumação dessa política está dando resultados ou já é um fragoroso desastre?

PRA: Não é verdade que o Brasil adotou um alinhamento automático no campo diplomático, no seguimento do golpe militar de 1964, ao estilo tosco como isso se exerceu em alguns episódios do imediato pós-guerra, sob o governo Dutra. O atual adesismo idiota de vários personagens do governo - presidente, familiares e o próprio chanceler acidental - não tem precedentes na nossa história diplomática, e constituiu algo profundamente vergonhoso para a diplomacia e para o próprio país. Isso vai nos afastar de diversos outros países, não porque eles sejam necessariamente antiamericanos (o que alguns são), mas porque ninguém gosta de países que não possuam identidade própria em suas relações exteriores. Países caudatários, diplomacias submissas, são tratados com desprezo pela comunidade internacional.

Qual a vantagem de nos tornarmos aliados preferenciais da OTAN Organização do Tratado do Atlântico Norte? Não há risco de sermos arrastados para conflitos dos Estados Unidos, como no Iraque?

PRA: Não há nenhum risco de nos envolvermos nas aventuras militares dos EUA, ou da própria OTAN, ao redor do mundo. Trata-se simplesmente de um expediente pelo qual nossos padrões e normas industriais se ajustam aos em vigor no âmbito da OTAN, o que sempre representa uma economia de escala (mas sem qualquer garantia de que benefícios advirão automaticamente para a indústria bélica do Brasil). O que se espera é uma ampliação das cadeias de valor nessa área, no caso de um país, como o nosso, que participa muito pouco de outras cadeias de valor.

Seria vantajoso para o Brasil ingressar na OCDE- Organização para Cooperação e Desenvolvimento Econômico?

PRA: Pode ser, mas não creio que seja necessário absolutamente. O Brasil pode adotar, voluntariamente, todos os padrões que são seguidos pelos países da OCDE sem precisar aderir à organização, e pode fazê-lo da maneira mais adequada ao seu próprio ritmo de integração progressiva à interdependência global. Ser independente, mas estar 
sempre avançando nos melhores padrões da indústria mundial é o que de melhor podemos esperar para o Brasil. Devemos fazer aquilo que é bom para nós, não o que determinam quaisquer outros países, mas devemos estar conectados a todos os padrões e requerimentos básicos da globalização.

\section{Ganhamos algo em sair do OMC - Organização Mundial do Comércio? A exigência de saída da OMC foi uma traição de Trump a Bolsonaro?}

PRA: Não ocorreu, nem vai ocorrer nenhuma saída do Brasil da OMC, pois isso seria impossível. O que ocorreu foi uma renúncia, mas a pedido, do chamado tratamento especial e mais favorável para países em desenvolvimento, o que até pegou os "líderes" brasileiros de surpresa, na visita de Bolsonaro a Trump. Eles não tinham a menor ideia, pois são ineptos, sobre o significado da medida, que significa renunciar a certas rebaixas tarifárias e algumas outras disposições mais favoráveis em matéria de normas. Mas, esse episódio apenas revela como a atual equipe dirigente é inepta sob vários pontos de vista, inclusive devido ao seu adesismo idiota aos EUA e ao governo Trump. No seguimento dessa aceitação caolha, míope do ponto de vista dos interesses nacionais, diplomatas e economistas mais competentes se encarregaram de relativizar a aceitação e de jogá-la para um futuro indefinido, mas o mal já estava feito, pelo menos nas relações com os EUA e em eventuais novos acordos a serem negociados.

\section{O Brasil manteve sua posição no Conselho de Direitos Humanos da ONU.} Não é contraditório com os elogios que o Presidente tem feito a torturadores e a ditadores abomináveis, como Pinochet e Stroessner?

PRA: A maior parte das agências da ONU seguem esse "equilíbrio" regional, e principais aceitos mais ou menos mecanicamente de "rotação" entre os países, o que acaba redundando na "eleição" de alguns países com credenciais execráveis no plano dos direitos humanos e democracia. Apenas em casos excepcionais - um ditador que realmente pratica genocídio contra o seu próprio povo - ocorre uma "recusa política" do candidato, do contrário ele será eleito, inclusive com o voto de democracias plenas. Essa é uma hipocrisia conhecida nas relações internacionais, uma vez que os países acham que, se deixarem de seguir a alternância ou rotação, poderão ficar sem 
votos na próxima eleição, quando será a sua vez de ocupar tal vaga. Essa hipocrisia deve continuar.

Estamos desde abril de 2019 sem titular em Washington. Isso depois do Presidente anunciar (e depois recuar) seu filho como titular. Quais as consequências disso para as relações entre os dois países?

PRA: O espetáculo “diplomático” oferecido pelo atual governo é propriamente vergonhoso e jamais visto nos anais da nossa diplomacia. O presidente é um completo ignaro das normas e costumes mais elementares nas relações internacionais, e vai anunciando candidatos a postos diplomáticos em total descumprimento das normas usualmente seguidas nesse tipo de procedimento, quando confidencialidade e discrição são padrões seguidos antes da aceitação do designado pelo outro país. O rebaixamento determinado nas relações bilaterais também é inédito, pois normalmente se escolhe um diplomata experiente ou personalidade influente na vida internacional do Brasil, com conexões com parceiros atuando nas relações entre os dois países. Nestor Forster é um excelente funcionário diplomático, embora seja um embaixador recém promovido, e ainda vai ser testado no cargo que vai assumir na chefia da embaixada em Washington.

O que significa a destruição da inteligência no Itamaraty, subtítulo de seu livro mais recente?

PRA: Na medida em que o chanceler se submete, servilmente, a um pessoal despreparado no campo das relações internacionais - como são o próprio presidente, seus filhos e o guru de todos eles, expatriado na Virgínia -, a única consequência é reduzir decisões importantes no campo da política internacional do Brasil a ineptos, e mais ainda, a pessoas que se guiam não pela racionalidade, mas pelos preconceitos e pela ideologia, ou seja, pela irracionalidade.

Trump logrou recentemente a reformulação do NAFTA - Acordo de Livre Comércio da América do Norte. Ele tinha razão quando dizia que o tratado era injusto e precisava ser revisto? 
PRA: Trump é um completo ignorante em matéria de economia e de comércio internacional. Ele tem a mesma disposição, depois demonstrada aqui por Bolsonaro, de destruir tudo o que havia antes, para colocar outras coisas, ou nada, no lugar. Foi assim com o Obamacare e com medidas no campo da sustentabilidade ou das energias renováveis. Começou denunciando o TPP, um virtual acordo de livre comércio entre 12 grandes e pequenas economias da franja do Pacífico, que ainda assim foi assinado, a 11, sem a participação dos EUA. Com o NAFTA foi a mesma coisa: denunciado, mas substituído por acordos bilaterais com Canadá e México, que preservam os objetivos, mas introduzem dispositivos mais mercantilistas e protecionistas da parte dos EUA, o que só vai prejudicar os consumidores e as indústrias dos EUA, na medida em que impõem custos adicionais aos produtores e um descolamento da interdependência simbolizada em cadeias de valor. Como seus eleitores são ignorantes, pode até ser uma vitória política de Trump, mas se trata claramente de uma derrota para a economia.

\section{O USMCA - Acordo Estados Unidos, México e Canadá -, na sua opinião, foi} também uma vitória para os trabalhadores?

PRA: Esses acordos comerciais não são feitos para beneficiar em primeiro lugar os trabalhadores de determinadas indústrias ou setores da economia, que representam sempre uma determinada parcela da população. Eles são feitos para beneficiar TODA a população e, portanto, também os trabalhadores, com produtos e serviços mais baratos e de melhor qualidade. Trabalhadores e empresas serão deslocados, o que significa perdas setoriais, locais, temporárias; os ganhos de bem-estar, diluídos por toda a população, são bem maiores, mas menos visíveis do que essas "perdas" localizadas, que se tornam mais vocais no parlamento, na mídia. Consumidores beneficiados não se manifestam.

No final dos anos 90 e início dos anos 2000, as relações diplomáticas entre Brasil e Canadá viveram seu pior momento, em razão da disputa entre Bombardier e Embraer e em função do comércio de carne bovina. Como fica essa relação agora que a Embraer foi absorvida pela Boeing e que a criação ganadeira tem sido responsabilizada pelo avanço do desmatamento na Amazônia, sobretudo considerando ser o Canadá um país zeloso com a questão ambiental? 
PRA: Competição entre empresas é um dado incontornável de todas as economias de mercado, e nada muda nesse particular, a não ser que alguns concorrentes disponham ou de vantagens especiais - determinadas politicamente - ou de desvantagens criadas por outras normas e regulações, que não aquelas que emergem naturalmente da dinâmica dos mercados. Alegações ambientalistas podem ser usadas de má-fé por motivações protecionistas, ou de concorrência desleal. Cabe aos países atentar para normas e disposições existentes no cenário comercial internacional para não ter suas empresas indevidamente afetadas por acusações sem fundamento.

A transição e consolidação fiscal do Canadá no final dos anos 1990 serve de referência ao Brasil?

PRA: Não conheço particularmente esse aspecto das políticas econômicas do Canadá, mas, por princípio, por norma básica de qualidade das políticas econômicas dos países, qualquer consolidação fiscal é absolutamente indispensável para uma boa gestão das contas públicas. Os governos, os países, não precisam necessariamente apresentar orçamentos totalmente e sempre equilibrados, pois todos eles precisam administrar dívidas públicas, que podem crescer moderadamente ao longo do tempo, desde que feitas para fins de investimentos produtivos e para estímulo da produtividade, o que tornará o país mais rico no futuro. A construção da união monetária europeia se fez em torno de alguns princípios básicos, entre eles a imposição de um déficit orçamentário não maior do que $3 \%$ do PIB e uma carga total da dívida pública não maior de $60 \%$, o que parece critérios razoáveis de solidez fiscal. Estes indicadores servem também para o Brasil e o Canadá, e só podem ser ultrapassados em circunstâncias excepcionais.

\section{Brasil e Canadá enfrentaram com mais tranquilidade que outros países a} crise de 2008. No entanto os dois parecem cooperar pouco na área de regulação financeira. Por quê?

PRA: O Canadá é um país membro da OCDE e segue a coordenação que se desenvolve nesse âmbito nos temas da regulação financeira. Ambos, Brasil e Canadá, fazem parte do G-20 financeiro e são membros do BIS (Banco de Compensações Internacionais), o que indica que ambos seguirão padrões e normas de regulação financeira 
adequados a um número mais vasto de países. Não há motivo para cooperar especialmente e bilateralmente nesse terreno da regulação financeira, a não ser para facilitar ainda mais as transações entre ambos.

\section{O Canadá foi um entusiasta da falecida ALCA - Área de Livre Comércio das} Américas, que o governo FHC viu com ceticismo e o governo Lula enterrou. Como você percebe a trajetória dessa proposta?

PRA: A ALCA era uma proposta americana que tinha aspectos positivos e outros negativos, como quaisquer acordos internacionais, ou até medidas econômicas internas. No geral, livre comércio é sempre, e em qualquer hipótese, positivo para todos os países, embora alguns se eximam da abertura ampla e preservem protecionismos setoriais, subsídios localizados e, portanto, um comportamento desleal em face de outros países que liberalizaram amplamente suas economias. Sob a justificativa de que os EUA não abririam substancialmente seus mercados agrícolas - terreno no qual o Brasil é amplamente competitivo -, mas também para proteger indústrias que são "infantes” eternamente, o Brasil e outros países sabotaram esse acordo, o que eu considero um erro estratégico. Não que a ALCA no modelo americano fosse o mais perfeito dos acordos comerciais, mas ela era, de toda forma, uma aproximação ao livre comércio, o que sempre é positivo, ainda que deficiências subsistissem.

Um acordo de livre comércio entre o Brasil e os EUA, como está sendo prometido pelo atual governo, é viável, a médio prazo?

PRA: Não atribuo a menor credibilidade a esse tipo de anúncio político e, portanto, não discuto hipóteses improváveis na presente conjuntura. Seria um acordo bilateral, como os EUA já têm com quase todos os países da região, com exceção, justamente, dos membros do Mercosul, e os chamados "bolivarianos". Depois que a ALCA foi sabotada por Brasil (Lula), Venezuela (Chávez) e Argentina (Kirchner), quase todos os demais países negociaram acordos bilaterais com os EUA.

Brasil e Canadá tiveram em comum até 2018 a valorização do multilateralismo e do multiculturalismo. A despeito dessa convergência, as ações de cooperação efetivas entre os dois países seguiram tímidas. Por quê? 
PRA: A interface econômica, comercial, cultural, científica, geral entre o Brasil e o Canadá ainda é limitada, e não se pode esperar um crescimento artificial em breve prazo. Diplomatas e empresários dos dois países, assim como acadêmicos e artistas, podem trabalhar para aumentar e expandir a outros setores essas relações. Multilateralismo é apenas um método aberto, e não um objetivo de diplomacia bilateral, ao passo que multiculturalismo é uma característica própria a cada país, mas cada um em bases diferentes.

\section{Como você avalia os resultados da missão conjunta no Haiti?}

PRA: Toda e qualquer assistência humanitária é sempre positiva em situações de extrema pobreza, como é o caso do Haiti. Mas não podemos nos iludir: a correção dos problemas de um país cabe, em primeiro lugar, aos seus próprios líderes, dirigentes e elites de uma forma geral. Nenhum país pode esperar melhorar vivendo de assistência pública internacional, como infelizmente parece ser o caso do Haiti (e de vários outros países ao redor do mundo, especialmente na África). Missões humanitárias podem, no máximo, remediar urgências absolutas, mas nunca conseguirão corrigir problemas e deficiências estruturais longamente existentes.

\section{As posições do atual governo brasileiro no meio ambiente, na questão indígena,} desarmamento e direitos humanos podem contribuir para afastar Brasil e Canadá?

PRA: Certamente: assim como o Brasil de Bolsonaro está sendo virtualmente rejeitado pelas sociedades e até governos da Europa ocidental, é provável que isso ocorra igualmente no caso do Canadá. Governos não costumam rejeitar a convivência de outros governos, por simples normas de cortesia diplomática e de simpática entre os povos, mas situações extremas podem levar ao afastamento entre governos e rejeição de novos acordos de cooperação entre agências públicas e até instituições acadêmicas, com grandes prejuízos para suas respectivas populações.

Como você percebe a proposta de um acordo entre Mercosul e Canadá? Está avançando, tem chances de prosperar?

PRA: Pode até ser que avance e se realize, o que sempre será positivo, mas haverá como em outros acordos exceções, delongas na liberalização, subsídios setoriais. Não 
obstante, seria certamente bem vindo no plano das relações bilaterais entre o Canadá e os países membros do Mercosul.

\section{Como você percebe a atual crise diplomática entre China e Canadá?}

PRA: São pequenos incidentes, ou acidentes de percurso, envolvendo práticas desleais por parte de empresas, mas por vezes, também, armadilhas dos serviços de inteligência, atuando em benefício das companhias nacionais. Não tenho conhecimento suficiente para opinar nessa questão.

\section{O Canadá sempre defendeu o direito de suas empresas negociarem com} Cuba. Isso representa ruído nas relações com os Estados Unidos, pode prejudicar as relações com o Brasil, considerando o extremismo ideológico do atual governo?

PRA: Canadá e Brasil sempre pautaram suas relações internacionais por princípio e normas do Direito Internacional, que geralmente rejeitam ações e medidas unilaterais que não estejam previstas na Carta da ONU ou nas resoluções de seu Conselho de Segurança. Os Estados Unidos têm esse péssimo hábito de atuarem unilateralmente, e se utilizam para tanto de seu enorme poder militar, econômico, financeiro, e sua capacidade de pressão sobre outros países. O governo Trump representa, aliás, uma exacerbação desse péssimo hábito. Canadá e Brasil deveriam continuar pautando sua diplomacia por uma adesão irretocável aos princípios do Direito Internacional, mas aparentemente o governo Bolsonaro se dispõe a seguir o governo Trump nesse tipo de desafio às relações internacionais, o que seria péssimo para os padrões historicamente observados pela diplomacia brasileira. O governo Bolsonaro já seguiu o governo americano e o de Israel, na questão das sanções unilaterais impostas a Cuba pelos EUA, o que é um registro lamentável, na medida em que significa o afastamento do Brasil do Direito Internacional. Posteriormente, a diplomacia brasileira, num gesto igualmente lamentável para nossa postura pregressa, aderiu imediatamente ao chamado "Plano Trump" para a "paz" na Palestina, o que nenhum outro parceiro dos EUA na OTAN o fez, pelo seu evidente desequilíbrio e injustiça para o povo palestino. Esse tipo de adesismo sabujo é algo deplorável nos anais da diplomacia brasileira. 
Nos EUA há certa euforia com o Brexit. Como o Canadá está reagindo a esse tema?

PRA: Eu não diria que nos EUA existe euforia com o Brexit. Como o presidente Trump é antiglobalista, antimultilateralista e, portanto, anticomunitário, ele se vangloria com a nova postura isolacionista e nacionalista da Grã-Bretanha, pois ela corresponde à sua própria postura em geral, no campo das relações internacionais. Suponho que o Canadá manterá a necessária discrição, como política de Estado, nessa questão, que cabe ao povo britânico e a seu governo encaminhar da melhor forma, sabendo, porém, que ocorrerão turbulências no comércio bilateral, antes reguladas no plano comunitário, e que terão de ser regidas por novas normas e princípios. Tudo isso é uma enorme perda de tempo e esforços, com a regulação burocrática dessas relações, que passam do plano multilateral ao estritamente bilateral. Suponho, mesmo sem saber a postura específica do governo canadense sobre o Brexit, que isso causará transtornos em toda a interface econômica, e até política e cultural, entre ambos países. O Brexit é, antes de mais nada, um imenso erro de cálculo dos governos conservadores, e tanto o Reino Unido quanto a União Europeia sairão enfraquecidos e diminuídos com a sua concretização.

\section{Nota}

1 Doutor em História Social pela Universidade de São Paulo (USP, pesquisador associado ao Núcleo Diversitas (USP), São Paulo, Brasil. gunter@terra.com.br 